\title{
Reflexões sobre o conceito e a ocorrência do processo de gentrification no Parque Histórico do Pelourinho, Salvador - BA
}

\author{
Reflections on the concept and occurrence \\ of the gentrification process in the Parque \\ Histórico do Pelourinho, Salvador - BA
}

Daniel de Albuquerque Ribeiro

\section{Resumo}

Gentrification é um processo urbano que ocorre em bairros históricos comumente centrais. Estando associado às transformações desencadeadas em um momento posterior à década de 1930, o processo implica a substituição de uma população de baixo poder aquisitivo por outra mais abastada. Essas características agregam a esse objeto de estudo um tipo específico de recorte espacial, temporal e social. A presente análise sobre o processo de gentrification poderá ser dividida em três momentos. 0 primeiro com a reflexão sobre o conceito em si, o segundo com a análise de alguns estudos de caso e o terceiro com o estudo de caso sobre o Parque Histórico do Pelourinho, Salvador, Bahia, que abrange três bairros tradicionais da cidade: Maciel, Carmo e Santo Antônio Além do Carmo.

Palavras-chave: gentrification; Parque Histórico do Pelourinho; Salvador; processos urbanos; agentes modeladores.

\begin{abstract}
Gentrification is an urban process that usually occurs in central or downtown historic neighborhoods. Being associated with the transformations that took place soon after the decade of 1930, it implies the replacement of a low-income population by another, more prosperous, one. These characteristics provide this object of study with a specific spatial, historical and social outline. The analysis of the gentrification process can be divided into three stages. The first presents a reflection on the concept, the second analyzes some case studies, and the third discusses the case study of the Parque Histórico do Pelourinho (Historic Park of Pelourinho), in the city of Salvador, which encompasses three traditional neighborhoods: Maciel, Carmo and Santo Antonio Além do Carmo.
\end{abstract}

Keywords: gentrification; Parque Histórico do Pelourinho; Salvador; urban processes; modeling agents. 


\section{Introdução}

\section{Gentrification ou gentrificação?}

Com relação a possíveis críticas ao fato de se trabalhar a palavra gentrification, sem traduzir, é válido traçar algumas explicações do motivo pelo qual se optou por isso. Primeiramente é preciso responder a argumentos baseados no nacionalismo e na importância de se reforçar a língua portuguesa. Tais alegações não condizem com o mundo científico, e ao mesmo tempo, parecem alheias à realidade do cotidiano do brasileiro que é repleto de palavras estrangeiras. Ninguém diz que vai ao centro de compras e sim ao shopping center, do mesmo modo se esse artigo estiver sendo lido em um computador, provavelmente o leitor estará usando um mouse, ao invés de um rato. 0 estrangeirismo é ampliado se incluirmos as palavras originárias de outras línguas. Sendo assim, há necessidade em se nacionalizar um termo alóctone, somente por questões patrióticas? E ainda se acrescenta mais uma indagação. Deve-se traduzir um termo, mesmo que essa tradução não faça o menor sentido ou se não houver nenhum correspondente mais coerente? Já há mais de um século que Schopenhauer debatia sobre a escrita, e em um de seus textos, o mesmo faz menção à mistura entre patriotismo e ciência.

Deve ser mencionado aqui, só de passagem, o fato de que o patriotismo, quando tem a pretensão de se fazer valer no reino das ciências, não passa de um acompanhante indecente, do qual é preciso se livrar. Quando se trata de questões puras e gerais da humanidade e quando a verdade, a clareza e a beleza devem ser os únicos critérios, o que pode ser mais impertinente do que a tentativa de pôr na balança a preferência pela nação à qual certa pessoa pertence e, em nome desse privilégio, ou cometer uma violência contra a verdade, ou uma injustiça contra os grandes espíritos de nações estrangeiras para destacar espíritos inferiores da própria nação? No entanto, encontramos exemplos dessa vulgaridade todos os dias, entre os escritores de todas as nações europeias. Esse traço foi satirizado por Iriarte na trigésima terceira de suas ótimas fábulas literárias. (Schopenhauer, 2009, p. 35)

0 problema em se traduzir gentrification, para gentrificação não reside somente na ausência de sentido do termo em português. Isso, por si só já seria um barbarismo concordando assim com a opinião de Vasconcelos (2011, p. 21) "A noção de "gentrificação", barbarismo que não tem sentido nas línguas latinas, pois a palavra vem do inglês gentry, ou seja pequena nobreza (...)". No entanto, a inconveniência da tradução do termo, reside na perda do significado que o mesmo carrega e também na ausência de um indicativo que chame a atenção para o fato de que o vocábulo foi cunhado em outras terras.

Um exemplo clássico sobre o perigo das traduções pode ser dado com a palavra amor. Seu entendimento como um sentimento não somente distorceu seu real significado, como reduziu a um único termo quatro conceitos experimentados pelos gregos para designar distintas ideias que em nossa língua falamos como sendo uma só. 
Se bem me lembro, uma dessas palavras era eros, da qual se deriva a palavra erótico, e significa sentimentos baseados em atração sexual e desejo ardente. Outra palavra grega para amor, storgé, é afeição, especialmente com a família e entre os seus membros. Nem eros nem storgé aparecem nas escrituras do Novo Testamento. Outra palavra grega para amor era philos, ou fraternidade, amor recíproco. Uma espécie de amor condicional, do tipo "você me faz o bem e eu faço o bem a você " Finalmente os gregos usavam 0 substantivo ágape e o verbo correspondente agapaó para descrever um amor incondicional, baseado no comportamento com os outros, sem exigir nada em troca. É o amor da escolha deliberada. Quando Jesus fala de amor no Novo Testamento, usa a palavra ágape, um amor traduzido pelo comportamento e pela escolha, não o sentimento do amor. (Hunter, 1998, pp. 77-78)

A importância de se conservar termos, no mundo científico, pode ser exemplificada com o GPS (Global Positioning System). A mesma sigla utilizada nos Estados Unidos é adotada em qualquer lugar do planeta. Não é difícil deduzir que a manutenção de uma palavra facilita a comunicação entre os cientistas de regiões distintas, que falem diferentes línguas. De qualquer modo, sabe-se que as traduções são comuns, mas, ainda assim, elas conservam um sentido. 0 aportuguesamento de gentrification para "gentrificação" é desprovido de qualquer sentido para quem ler. Se seguirmos o vetor na direção contrária, podemos tomar como exemplo a expressão boia fria. Se um tradutor, transladar um texto do português para o inglês e encontrar a palavra boia fria, o mesmo conservará boia fria em sua tradução, e não boei frei ou cold food. Qualquer tentativa de mudar um termo que só faz sentido em sua língua original parece incoerente.

Quando se trabalha gentrification na sua definição original chama-se uma primeira atenção para o fato de que a expressão não surgiu no Brasil e logo deve ser analisada com cuidado. Primeiro por ter sido concebida em outra realidade e segundo para compreender o que ela significa. No entanto, o que é gentrification? É importante entender a origem do termo e a partir daí começar a debater as diferentes formas que o mesmo já foi pensado.

Há dois tipos de denominação para os nobres nos países que compõem o Reino Unido. 0 peerage é a alta nobreza, aqueles que possuem títulos, como duques, marqueses, condes, viscondes e barões. A gentry diz respeito aos pequenos nobres ingleses. 0 termo gentrification foi usado pela primeira vez pela socióloga Ruth Glass em 1964, para explicar o fenômeno da vinda desses "pequenos nobres ingleses" para o centro histórico de Londres. A palavra por sua vez é anterior ao século XX. Ela deriva do francês antigo genterise que significa de nascimento nobre ou nascimento suave. Esse termo corresponderia na Inglaterra à aristocracia rural que compunha a posição de senhores na estratificação social da sociedade anglo-saxônica. (Ribeiro, 2011)

A partir dessa explicação, é possível se dar uma primeira e incompleta definição sobre o conceito de gentrification, uma vez que action significa ação, logo o processo implica uma ação de enobrecer uma área. Contudo, não se trata de qualquer tipo de enobrecimento, como a palavra portuguesa nobre pode levar a entender, mas de um tipo específico de nobreza, uma pequena nobreza - gentry. Logo, entende-se que não é o rico quem compõe 
o recorte social do processo em questão e, sim, uma população similar à classe média. Ao menos inicialmente, o conceito foi pensado assim, mas como veremos adiante, as interpretações e análises sobre o próprio mudam de autor para autor.

No entanto, apesar das ressalvas, será recorrente a utilização de gentrificação durante 0 texto. Isso por conta das inúmeras fontes consultadas e também pelo fato de que a grande maioria das traduções e dos autores brasileiros trabalha com a palavra aportuguesada. Isso por sua vez não desqualifica o esforço deste artigo em chamar a atenção para o conceito em si. É importante destacar que o presente autor acredita que, com o tempo, a palavra gentrificação será incorporada ao dicionário português, mas de qualquer modo é válido deixar aqui o registro das reflexões já comentadas.

\section{Do conceito ao recorte espacial, temporal e social}

0 processo de gentrification tem três recortes específicos, um espacial, um social e um temporal. 0 recorte espacial é comumente associado aos centros históricos das cidades; no entanto, ao se aprofundar mais na leitura sobre o processo, percebe-se que ele se dá não somente no centro histórico, como em bairros centrais e que tenham características históricas mais destacadas do que em outros pontos da cidade.

Já o recorte temporal costuma ser negligenciado nas definições, todavia ele é fundamental, pois estabelece o momento inicial do fenômeno cujo termo foi cunhado pela primeira vez por Ruth Glass (1964). Sendo assim, é preciso compreender que antes da gentrification acontecer, ocorreu outro processo, o de difusão, que nesse caso se deu com a saída das famílias mais abastadas dos bairros centrais em direção a áreas mais remotas e longe dos incômodos urbanos. A massificação desse processo foi intensificada com a segunda revolução industrial. Esses dois fatores definem o ponto de partida do esvaziamento dos centros, seguido pela ocupação desses por famílias de baixa renda. Portanto, não se pode dissociar a gentrification da pós-modernidade. Isso é uma chave, pois como será visto mais adiante, já houve ações similares ao processo em questão, mas fora do recorte temporal e, talvez por isso, fora da mesma lógica.

0 recorte social é estabelecido a partir da substituição de uma população de baixo poder aquisitivo por outra mais abastada. Entretanto, esse recorte é ainda mais especificado por alguns autores. No caso de Smith, ele se refere aos trabalhadores de colarinho branco (Smith, 1996), e ainda aos Yuppies (Smith, 2006). E é comum aos autores que trabalham o conceito fazer referência a um público específico que se interessa pelos bairros centrais. São artistas, universitários, professores ou pessoas que se identificam com o estilo boêmio de vida do centro. Deve-se destacar que esses mesmos agentes podem vir a ser substituídos em um momento posterior por ação dos agentes econômicos e promotores imobiliários.

A partir dessas reflexões, pode-se definir o entendimento clássico da gentrification como um processo urbano específico de bairros centrais e com uma historicidade que se destaca do restante da cidade. Esse fenômeno se inicia após o processo de difusão da população mais rica em direção a áreas periféricas e a 
ocupação dos centros por uma população mais pobre em um período que coincide com a pós-modernidade. Por fim, ele é caracterizado pela substituição dessa população pobre, por outra de maior poder aquisitivo, com um estilo específico de vida e, em alguns casos, até mesmo de se vestir e de se comportar. Contudo, deve-se deixar claro que esse é um entendimento inicial e que engessá-lo ou querer aplicá-lo em todas as realidades consistirá em erro grave.
Tudo isso não aconteceu sem reações. Enquanto nos ruidosos anos oitenta a linguagem e a realidade da gentrificação haviam invadido a mídia, e novos jovens urbanos das classes médias passavam a ser chamados de yuppies, os efeitos da gentrificação se tornaram mais evidentes. 0 número de famílias expulsas de suas moradias subiu vertiginosamente, assim como o número de sem-teto, estimado em cerca de 100 mil, ou seja, 1,5\% da população da cidade. (Smith, 2006, p. 68)

Em seu estudo, Smith (2006) também

\section{Neil Smith e as ondas de gentrification, o caso de Nova York}

Ao observar o bairro do Soho em Nova York, o geógrafo Neil Smith (2006) traçou importantes teorias a respeito da gentrification. Uma delas divide sua ocorrência em três ondas. "A primeira poderia ser chamada de gentrificação esporádica, a segunda seria a consolidação do processo; enquanto na terceira estamos diante de uma gentrificação generalizada" (Smith, 2006, p. 63).

A primeira onda ocorreu nas décadas de 1950 e 1960. Nessa fase, junto com a vinda de uma população de classe média para os bairros do centro, era observada a presença relevante de instituições financeiras promovendo a recuperação das áreas tidas como decadentes. A segunda onda se dá do final da década de 1970 a 1989 e é caracterizada pelo que Smith denomina como consolidação. Trata-se da intensificação pela ação dos agentes econômicos e promotores profissionais. Além disso, é nessa fase que se registra a reação organizada pelos antigos moradores que foram expulsos. relata um período de recessão, que foi taxado por alguns como desgentrification, mas como o autor afirma o processo não parou completamente. Além disso, é possível também fazer a conexão dessa desaceleração das ações especulativas e desvalorização das áreas, como uma estratégia dos agentes econômicos e promotores imobiliários, que é melhor definida por Smith (2006), como rent gap. Ainda sobre a recessão é válido mencionar os comentários do próprio sobre as áreas que não foram completamente afetadas.

Nos bairros mais marginais, onde a primeira transformação marcante emergiu durante a segunda onda - Williamsburg e Fort Green, no Brooklyn, a cidade de Long Island, no Queens, Hells's Kitchen, em Manhattan, e muitas outras - a gentrificação certamente esgotou as fontes para outros tipos de investimentos em imóveis residenciais. Também no Harlem, a reabilitação das casas de tijolo, que aconteceu no fim dos anos oitenta, acabou definitivamente. Mas nos bairros mais centrais, do Soho e Upper West Side, o processo não parou completamente no início dos anos noventa; na verdade, ele prosseguiu até mais que de forma pontual. (Smith, 2006, p. 71) 
Em 1993, o processo é retomado e ampliado em 1996, quando ocorre sua generalização para áreas mais afastadas das centrais. Tal fato já relativiza o próprio recorte espacial. 0 autor explica que a opção por trabalhar com Nova York se deu pelo motivo de que: "em quase quatro décadas essa cidade viu evoluir sua gentrificação de uma anomalia local para uma estratégia urbana articulada" (Smith, 2006, p. 73). Para ele, essa estratégia urbana se torna global tomando características peculiares em cada lugar onde ocorre. Essa generalização do processo apresenta cinco características interligadas que são "o novo papel do Estado; a penetração do capital financeiro; as mudanças nos níveis de oposição política; a dispersão geográfica; e a generalização da gentrificação setorial, já evocada" (Smith, 2006, p. 74).

Com isso, a terceira fase é caracterizada pela participação do Estado em parceria com o capital privado e os governos locais, ao mesmo tempo em que o capital global se faz presente nos investimentos feitos. Smith também chama a atenção para a estratégia de desinvestimento feita nos bairros abandonados e para um conjunto de ações que atendem a um grupo que visa certos interesses econômicos. A articulação entre diversos aspectos dessas estratégias proporcionarão que essas cidades se tornem globais.

Uma nova "gentrificação complexa" e institucional inaugura agora uma renovação urbana de dimensão classista. Essa gentrificação classista complexa conecta o mercado financeiro mundial com os promotores imobiliários (grandes e médios), com o comércio local, com agentes imobiliários e com lojas de marcas, todos estimulados pelos poderes locais, para os quais os impactos sociais serão doravante mais asseguradas pelo mercado do que por sua própria regulamentação. (Smith, 2006, p. 79)

\section{Criekingen - Bruxelas}

De uma coletânea de estudos realizados no livro De Volta à Cidade (Zachariasen et al., 2006), para os propósitos deste artigo, o estudo de Criekingen (2006) merece destaque por conta da rigidez com que interpretou e aplicou o conceito de gentrification. Ele avalia o processo a partir de parâmetros definidos por sua visão a respeito do tema. Aliado a isso, estabelece quem seriam os agentes promotores e por fim trabaIha com dados estatísticos. Com isso, ele conclui a respeito da inexistência de gentrification em Bruxelas. Contudo, parece claro que o autor só chegou a tal constatação por não compreender que a realidade nova iorquina não poderia ser igualada à de outros lugares, sendo assim terminou por engessar o conceito. Além disso, Criekingen não relativiza a interpretação dos dados estatísticos. Todavia, ele oferece uma quantidade de reflexões de grande relevância para a compreensão do que seria o processo, a começar pela própria definição.

Eu proponho falar de gentrificação quando estamos em presença de um processo de produção de um espaço sofisticado e homogêneo a partir de um espaço urbano originalmente degradado (seja ele habitado ou não), o qual, desde então, apresenta transformações no seu aspecto exterior pela renovação das edificações existentes (conservando ou transformando a função original dos edifícios) ou pela construção de novos edifícios, e que se assenta sobre uma mobilidade residencial que ocorre 
pela instalação de uma nova população, e, se for o caso, pela partida da população previamente existente, mais ou menos forçada por diferentes tipos de pressão. (Criekingen, 2006, p. 100)

Se por um lado o autor traz uma excelente definição para o processo, por outro no momento em que faz sua análise, ele o enrijece. A flexibilidade talvez pudesse levá-lo a uma constatação diferente. 0 fato é que tudo indica que ele se prendeu aos padrões de gentrification das cidades globais, como ele mesmo informa. Além disso, ele também caracterizou um perfil para os tipos de "gentrificadores", como se fossem somente yuppies. Por último, ao analisar o processo pelo viés estatístico tomando como base a renda das famílias em uma proporção geral, Criekingen desconsiderou as substituições que ocorreram como sendo frutos de uma gentrification, por conta de uma posição relativa a de outras camadas mais ricas da cidade de Bruxelas. Ainda há mais um fator a ser questionado, pois ao constatar casos pontuais do processo, o autor não os considerou expressivos para que sejam enquadrados como existindo gentrification na cidade.

Se os critérios estabelecidos por Criekingen forem seguidos, então de todos os relatos que serão apresentados neste artigo, talvez somente o de Nova York será definido como gentrification. Existem mais questões que passaram despercebidas pelo autor em questão. Dentre elas está o fator da intencionalidade de um agente versus o grau de sucesso das suas ações. 0 impacto socioespacial que as ações possam estabelecer. E por fim a expressividade do relativismo pontual de fatos.
Um conceito interessante trazido por Criekingen é o de upgrading, definido como a ascensão social da própria população, o que permite que a mesma melhore suas condições de habitação. Vale destacar que provavelmente essa é uma realidade comum e paralela à maioria dos casos de gentrification. Contudo, fica clara a existência do processo em Bruxelas, quando o autor define o que chama de "gentrificação marginal".

Trata-se de um processo pelo qual certos bairros centrais se vêm tomados por uma população jovem, muito escolarizada, globalmente mais abastada que os antigos moradores, sem, no entanto, serem "os ricos" na escala da cidade. (...) Dito de outro modo, a gentrificação marginal não é um estágio transitório para a chegada de uma gentrificação total a mais ou menos curto prazo. (Criekingen, 2006, p. 100)

É válido reafirmar que a dureza com que o conceito foi tratado pelo autor o leva a tais conclusões. Isso é um exemplo da importância de não somente se entender a origem e o significado do termo, mas o que ele é de verdade. Em outras palavras quais são os principais elementos que o compõem? É preciso levar em consideração o entendimento a respeito dos três recortes, mais as ideias de Smith sobre as relações do processo com o capital internacional e com as estratégias dos agentes econômicos. A partir disso, teremos os elementos principais para uma compreensão sobre gentrification. Partindo desse ponto, é preciso ter a sensibilidade para perceber as peculiaridades e diferenças de cada lugar onde ele ocorrerá. 


\section{Relação entre gentrification com a Teoria do Caos e os estudos de Bauregard}

A ideia de que o processo de gentrification poderia ser facilmente relacionado com a Teoria da Complexidade e a Teoria do Caos sempre me pareceu bastante coerente. Primeiramente porque a quantidade de elementos que compõem e interferem em sua dinâmica é quase infinita. Segundo, pelo fato de que é impossível prever com exatidão o futuro de uma área que passe por um processo urbano. Dessa maneira, um lugar que tenha alta especulação imobiliária pode repentinamente entrar em uma fase de desvalorização. Do mesmo modo, um lugar abandonado e rejeitado por maior parte da população pode receber um projeto urbanístico que eleve sua procura, e com isso os preços de seus lotes. Nessa combinação de elementos, temos diferentes agentes modeladores e diferentes papéis desempenhados por agentes da mesma categoria. Um acontecimento no Japão pode influenciar um processo em Salvador. A mudança de um fator da bolsa de valores, ou na moeda europeia, pode interferir nas levas de turistas - quantitativa e qualitativamente - e consequentemente em um possível público para consumir as cidades brasileiras e, em alguns casos, posteriormente adquirir residências nos centros.

Reconhecendo a importância do materialismo histórico e das teorias elaboradas por Smith para o entendimento da gentrification, Bauregard (1996) sugere que é preciso avançar para um entendimento do processo através da Teoria do Caos. Para chegar a tal ponto, aponta três fraquezas teóricas relacionadas à rent gap. A primeira estaria no fato de se utilizar o desenvolvimento desigual para explicar a diferença de renda, quando tanto uma coisa quanto outra deveria ser pensada a partir das tendências estruturais do capitalismo. 0 segundo ponto fraco consiste na inexistência de tentativa para explicar a diversidade do processo. 0 terceiro ponto diz respeito à desatenção do papel da reprodução e do consumo no fenômeno estudado.

Fazendo referência à Teoria do Caos, ao continuar sua explanação, o autor explica que gentrification deve ser considerado como um conceito caótico. Primeiramente porque é necessário levar em consideração as diversidades de casos que envolveram diferentes tipos de indivíduos. E em segundo lugar, porque é importante pensar em distintas tipologias para o fenômeno ao invés de reunir tudo em uma única explicação.

The diversity of gentrification must be recognized, rather than conflating diverse aspects into a single phenomenon. Thirdly, the above observations suggest that a diversity of social forces and contradictions within the social formation cohere in some fashion to bring about various types of gentrification. Moreover, it additionally suggests that gentrification is not inevitable in older declining cities. (Beauregard, 1996, p. 40)

Dentre as possibilidades relativas ao processo, Bauregard traça dois extremos, indo do total abandono de um bairro até o realce de áreas que não necessariamente estão deterioradas. Ele aborda o exemplo clássico da saída da classe média dos bairros centrais, tendo suas moradias ocupadas por famílias de menor renda. Também trata a respeito de outra 
situação em que habitações de baixo custo são criadas a partir do uso misto de distritos industriais ou armazéns estabelecidos antes da Segunda Guerra. 0 autor amplia o debate ainda para a questão que envolve a população afetada e as relações a serem pensadas a partir desse grupo. Mesmo concordando com as ideias de Bauregard, em 2011 fiz algumas ressalvas com relação a sua abordagem sobre as contribuições de Smith.

Algumas ressalvas precisam ser feitas com relação ao conjunto teórico apresentado. Primeiro, parece que muitos dos pontos considerados por Bauregard como fracos em Smith foram mais produto de um foco do primeiro no rent gap do que em toda explicação que é apresentada pelo segundo. Ainda assim, em todo 0 debate teórico que foi realizado até 0 momento, só foram trabalhados os casos de países situados no topo da cadeia econômica mundial. Além disso, a própria realidade geográfica, jurídica, cultural, histórica e econômica desses países diverge muito dos de outros países no mundo. (Ribeiro, 2011, p. 101)

\section{Antes da gentrification e o milagre sem o nome do Santo}

Reclus (2010) em um texto datado de 1896, cujo titulo é Renovação de uma cidade, trata a respeito de Edimburgo e do contexto que se encontrava seu centro - High Street, muito semelhante ao dos casos de gentrification antes de passar pelo processo.
De ruína em ruína High Streeet tornou-se um local de miséria, um bairro sórdido. Prostitutas estendiam seus colchões de palha sobre antigos parquetes; chaminés monumentais, forradas de madeiras nobres e decoradas de esculturas, eram fechadas e transformadas em toaletes, nos wynds ou pátios, nos closes ou nas extremidades dos corredores, o lixo acumulava-se a vários metros de altura. 0 bairro insuportavelmente fétido, tais becos sem saída, tais ruelas ainda são sentinas de infecção. E a miséria ali pulula, lixo humano sobre o lixo das coisas. (Reclus, 2010, p. 85)

Ele relata sobre a ação de um grupo liderado por Patrick Geddes que tinha intenções de melhorar o lugar e agiram como verdadeiros agentes promotores da gentrification. No entanto, não é correto dizer que as ações foram relativas ao processo, não somente por terem se dado fora do recorte temporal, mas principalmente pela intencionalidade ser divergente da característica do fenômeno. Não havia intenção de lucro ou especulação, mas as ações de Geddes estavam mais próximas de uma visão filantrópica.

Logo se fez uma clientela de estudantes de ambos os sexos, de jovens professores e outros universitários. Resolveu proporcionar-lhes moradias menos odiosas, uma existência menos penosa. 0 local mais abjeto, talvez, de High Street, foi aquele pelo qual começou - tratava-se de um antro de meretrizes; ele não hesitou em comprá-lo e transformá-lo em University Hall; inclusive instalou o grupo dos estudantes. Ele não tinha dúvidas de que, mudando os ocupantes, a vizinhança mudaria, depois todo o meio. (Reclus, 2010, p. 88) 
É interessante que a concepção do projeto era social, tinha um caráter espacial e inclusive uma visão estratégica. Fica claro que, apesar de não se tratar de um projeto com bases que visassem o lucro, havia, contudo uma seleção do público que mereceria habitar aqueles espaços. Público esse com certeza "mais nobre" do que o das meretrizes que teriam transformado aqueles espaços em "antros".

Já em um segundo caso a ser comentado ocorre um claro exemplo de gentrification, mas que não tem o termo utilizado por quem o abordou. Trata-se da análise de Borja e Castells sobre Paris em 1975. Os autores iniciam relatando a respeito da precariedade e ausência de serviços essênciais, como de transporte, por exemplo.

De son côté, I'administration de la Ville de Paris, tout en partageant l'essentiel des tendances prospectives, et des promoteurs, et de l'évolution d'ensemble de la structure urbaine parisienne, a des problèmes particuliers: par exemple, la transformation accélérée de l'espace parisien exige un aménagement des services, des transports, des permis de construire, le groupement des travaux en tranches, en secteurs, etc. Mais surtout, dans la mesure où la Ville de Paris est en fait le gouvernement français, Paris étant la seule ville française à ne pas avoir une autonomie locale depuis la Commune de 1871, des intérêts politiques sont en jeu: implanter dans cet espace une population qui serve d'assisse électorale au parti du gouvernement (car I'U.D.R., majoritaire aux élections parlementaires depuis 1958, a toujours échoué dans ses tentatives d'organiser une base locale stable) et qui condamme à l'isolement le nouveau mouvement révolutionnaire issu de Mai 1968 et qui, pour le moment, trouve dans les grandes concentrations dans les rues de Paris la seule expression organisée et unitaire de la force potentielle. (Borja e Castells, 1975, pp. 22-23)

Borja e Castells abordam sobre o capitalismo descrevendo ações com características de gentrification por parte do governo francês. Eles as chama de Reconquista significativa de Paris. Essa reconquista do espaço urbano pelo governo que posteriormente passa "o bastão" para o setor privado. Esse por sua vez, que tem suas ações apoiadas pelo governo sob o pretexto de depuração de bidonvilles. Ao apontar um fator social, os autores revelam que o público de trabalhadores que é retirado dessas áreas é basicamente de imigrantes. No lugar onde se remove essa população, haverá mais rentabilidade com a instalação dos escritórios e apartamentos de luxo. Há também um destaque para a reestruturação espacial dos imóveis, onde um novo conforto é dado.

Ainsi, de la convergence des tendances de l'organisation spatiale dans une économie capitaliste développée des intérêts financiers des sociétés immobilières et dans le grand programme public de rénovation urbaine qui porte le titre significatif de Reconquête urbaine de Paris. Démarrant lentement dès 1956, battant son plein de 1964 à 1970 et passant ultérieurement le relais aux opérations privées, mais soutenues par l'administration, la Reconquête urbaine se présentait sous le couvert de l'élimination des taudis. En fait, il n'en est rien: secteurs les plus détériorés ne sont pas rénovés. Par contre, le sont ceux où la population ouvrière et immigrée est la plus importante, ceux où les bureaux et les logements de luxe seront les plus rentables. Un nouveau 
confort y est installé - mais pour une nouvelle population, celle qui y habitait étant rejetée dans la bandieue souséquipée. C'est la reconquête de Paris, mais la reconquête du Paris populaire par la nouvelle bourgeoisie des cadres supérieurs, par leurs lieux de travail et de loisir. Utilisant les prérogatives publiques d'expropriation, subventionnant avec des fond publics les travaux d'infrastructure nécessaires, la rénovation sert de fer de lance à la transformation de Paris en ville directionnelle et en gheto international pour cadres assoiffés de modernité, mais consommateurs d'une histoire qu'on transforme en musée et qu'on clôture (clôture = niveau des prix) pour s'y promener le samedi soir. (Borja e Castells, 1975, pp. 23-24)

\section{Contribuições de outros estudos}

Este tópico tem por objetivo mencionar a diversidade de alguns estudos realizados no livro $D e$ Volta a Cidade (Zachariasen et al., 2006), em que fica claro que, apesar da existência de elementos em comum a todos os casos abordados pelos autores, cada lugar experimentou diferenças peculiares.

0 primeiro exemplo é o de Barcelona. Nuria Claver, ao estudar Ciutat Vella (2006), identificou ações relacionadas com o planejamento estratégico. A começar com a promoção da cidade a partir dos Jogos Olímpicos. Combinado a isso, ocorreu a produção de um espaço a ser vendido para o turismo. Houve a construção de equipamentos urbanos que valorizaram o Centro, promovendo assim aumento do valor dos imóveis e da especulação imobiliária.
Segundo a autora, o Estado foi o principal agente da indução do processo.

A prefeitura baseou sua estratégia na localização das atividades econômicas consideradas "regeneradoras", assim como nos equipamentos culturais em pontos estratégicos. Dilyis Hill (1994) realizou uma análise das políticas de "regeneração" baseadas no surgimento de espaços de atração cultural e de atividades econômicas alternativas. Essas medidas foram promovidas pelo governo local e tinham como objeto principal diversificar o espaço público, objetivo este considerado como premissa necessária a qualquer dinâmica "auto-regeneradora" do bairro. (Claver, 2006, p. 157)

Além da ação do Estado, há um destaque para lentidão em que o processo se deu em contraposição aos casos dos países anglo-saxões. Combinado com isso deve-se destacar a mobilização social por meio dos afetados pela gentrification, que conseguiram se estabelecer nas proximidades do bairro da Ciutat Vella.

0 bairro de Saint-Georges, em Lyon, foi estudado por Authier (2006). Ao contrário de Barcelona, o Estado tenta impedir o avanço do processo. Contudo, os promotores imobiliários se aproveitam de brechas no sistema criado pelo próprio Estado e conseguem promover a gentrification. A autora ainda identifica três momentos, sendo o primeiro similar à gentrification esporádica e caracterizado por um movimento espontâneo da população para o lugar. 0 segundo dominado pela forte ação dos agentes imobiliários, e o terceiro pela preservação da população ao norte da poligonal gerando assim uma estratificação social do bairro. 
Outra abordagem interessante é a das cidades mexicanas, tratadas por Melé (2006). Dois fatores chamaram atenção nesse estudo. Primeiro, o desinteresse dos mexicanos ricos pelas áreas centrais. Segundo, uma forte cultura de habitar o centro pelos mais pobres. Esse habitar não somente no sentido de morar, mas de frequentar os espaços. Com isso, apesar das tentativas do estado mexicano de expulsar os mais humildes do centro e atrair os ricos para essa região, o sucesso dessas ações terminou sendo bastante limitado. Nesse aspecto, os mexicanos seriam parecidos com os brasileiros. Apesar disso, o autor chama a atenção para a existência de uma "gentrificação" pontual. 0 que é interessante de se mencionar, principalmente para servir de contraposição às ideias de Crienkingen sobre a inexistência do processo em Bruxelas.

\section{Gentrification no Parque Histórico do Pelourinho - Salvador/BA}

Dentre muitos motivos pelo qual a cidade do Salvador é conhecida, pode-se destacar sua importância no Brasil colonial. Sendo a segunda maior cidade do Império Português e primeira capital brasileira, posteriormente passa por uma lenta e gradual fase de declínio. Esse declínio iniciou-se a partir da transferência da capital do país para o Rio de Janeiro e com o abalo em sua economia açucareira devido à concorrência das Antilhas. No entanto, a capital baiana jamais perdeu sua importância como metrópole regional, além de sempre ter sido terra de muitas figuras ilustres que influenciaram na história brasileira. Salvador é ainda hoje um grande berço cultural com muitos artistas de renome internacional. Combinado a isso, ela conta com um rico conjunto urbanístico, que compõe seu centro histórico, conhecido como Pelourinho bem como seu entorno. É justamente nessa área que o processo de gentrification se desdobrou a partir da década de 1990.

No que tange à gentrification, há dois pontos em comum a se destacar entre Salvador e as cidades mexicanas relatadas por Melé (2006). Primeiro é que o processo em Salvador foi promovido pelo Estado, com a expulsão dos moradores do Pelourinho para execução de um projeto turístico. Segundo, é que a população mais rica da capital baiana não tem interesse em habitar o centro. Talvez por isso, inicialmente o público que mais adquiria casas na área não era soteropolitano e, sim, oriundo de outros estados e países, como ficou constatado em minha pesquisa de monografia (Ribeiro, 2008).

0 programa de Recuperação do Pelourinho, iniciado em 1991, foi um marco no que diz respeito à substituição populacional na área. Seu objetivo era recuperar as estruturas físicas em um projeto a ser realizado em etapas. Esse projeto foi duramente criticado pela forma como foi executado. 0 mérito do programa consiste no fato de ter recuperado diversas edificações que se encontravam em estado de ruína. No entanto, junto com isso foi realizada uma limpeza social da área para que a mesma pudesse se enquadrar aos moldes do turismo. Essa expulsão dos moradores mais pobres agradou considerável parte da classe média, que se sentia incomodada com o fato de ser o Pelourinho local de prostituição, alta criminalidade e frequentado por uma população 
sem recursos. De qualquer modo, foi essa população expulsa que, em conjunto com a ação de empresários locais, gerou bases para a efervescência cultural do lugar. Trata-se de diversas manifestações artísticas e populares, que se deram a partir de meados da década de 1980. Um exemplo dessas manifestações é Benção do Pelô, que foi a base para o surgimento da famosa banda percussiva Olodum.

É importante mencionar que a área já estava em uma decadência que se arrastava desde 1930, quando se intensificou o processo de difusão na cidade, com a saída da população mais abastada do centro, principalmente em direção à orla marítima. Não muito diferente, da maioria dos outros lugares que tiveram o processo de gentrification, as edificações abandonadas começaram a ser ocupadas por uma população de baixa renda que se fixava nesses locais transformando-os em cortiços. É interessante chamar a atenção para o fato de que a partir da década de 1930 os movimentos migratórios no país começaram a se intensificar, principalmente o êxodo rural. Sendo assim, a grande maioria desses novos moradores do centro era originária de outros municípios do estado da Bahia ou do Nordeste brasileiro. Com o declínio da área, se iniciam as primeiras ações e projetos visando a recuperação do Pelourinho, como é verificado no Quadro 1, que mostra a cronologia de medidas tomadas que buscavam intervir no centro da cidade.

Quadro 1 - Políticas públicas para o Centro Histórico de Salvador

\begin{tabular}{|c|c|c|}
\hline Ano & Ação & Instituição \\
\hline 1937 & $\begin{array}{l}\text { Criação do Serviço do Patrimônio Histórico e Artístico Nacional; } \\
\text { tombamento de monumentos }\end{array}$ & SPHAN \\
\hline 1959 & Medidas de proteção e obras de conservação & SPHAN \\
\hline 1967 & $\begin{array}{l}\text { Criação da FPACBA (IPAC). Promoção da conservação do patrimônio } \\
\text { artístico e cultural da Bahia }\end{array}$ & Governo da Bahia \\
\hline 1971 & $1^{\text {a }}$ etapa do Plano de Recuperação do Pelourinho & IPAC Seplan/PR \\
\hline 1972 & Plano de Desenvolvimento da Comunidade do Maciel & IPAC, PMS, UFBA \\
\hline 1976-1979 & Restauração de imóveis e instalações de serviços públicos e privados & IPAC \\
\hline 1977-1979 & Plano Diretor do Pelourinho (PLANDIP) & Conder, IPAC \\
\hline 1978 & Proposta de Valorização do Centro Histórico de Salvador & Conder \\
\hline $1981-1985$ & Projeto Centro Administrativo Municipal Integrado (CAMI) & Oceplan, PMS \\
\hline $1981-1982$ & Projeto de Recuperação Habitacional do Centro Histórico (Pelourinho) & IPAC, UIS/HOAB BNH \\
\hline 1983 & Criação do Escritório Técnico de Licenças e Fiscalização & IPAC, PMS, SPHAN/FNPM \\
\hline 1986 & $\begin{array}{l}\text { Criação da Fundação Gregório de Matos (FGM). Criação do Programa } \\
\text { Especial de Recuperação dos Sítios Históricos de Salvador }\end{array}$ & PMS \\
\hline 1986 & $\begin{array}{l}\text { Seminário do Programa Nacional de Recuperação e Revitalização de } \\
\text { Núcleos Históricos }\end{array}$ & MinC, MDU \\
\hline 1987 & Criação do Parque Histórico do Pelourinho & FGM-PMS \\
\hline $1991-2006$ & Programa de Recuperação do Centro Histórico & IPAC-Conder \\
\hline
\end{tabular}

Fonte: Bonfim (2007). 
Figura 1 - Vetores da especulação no Parque Histórico do Pelourinho

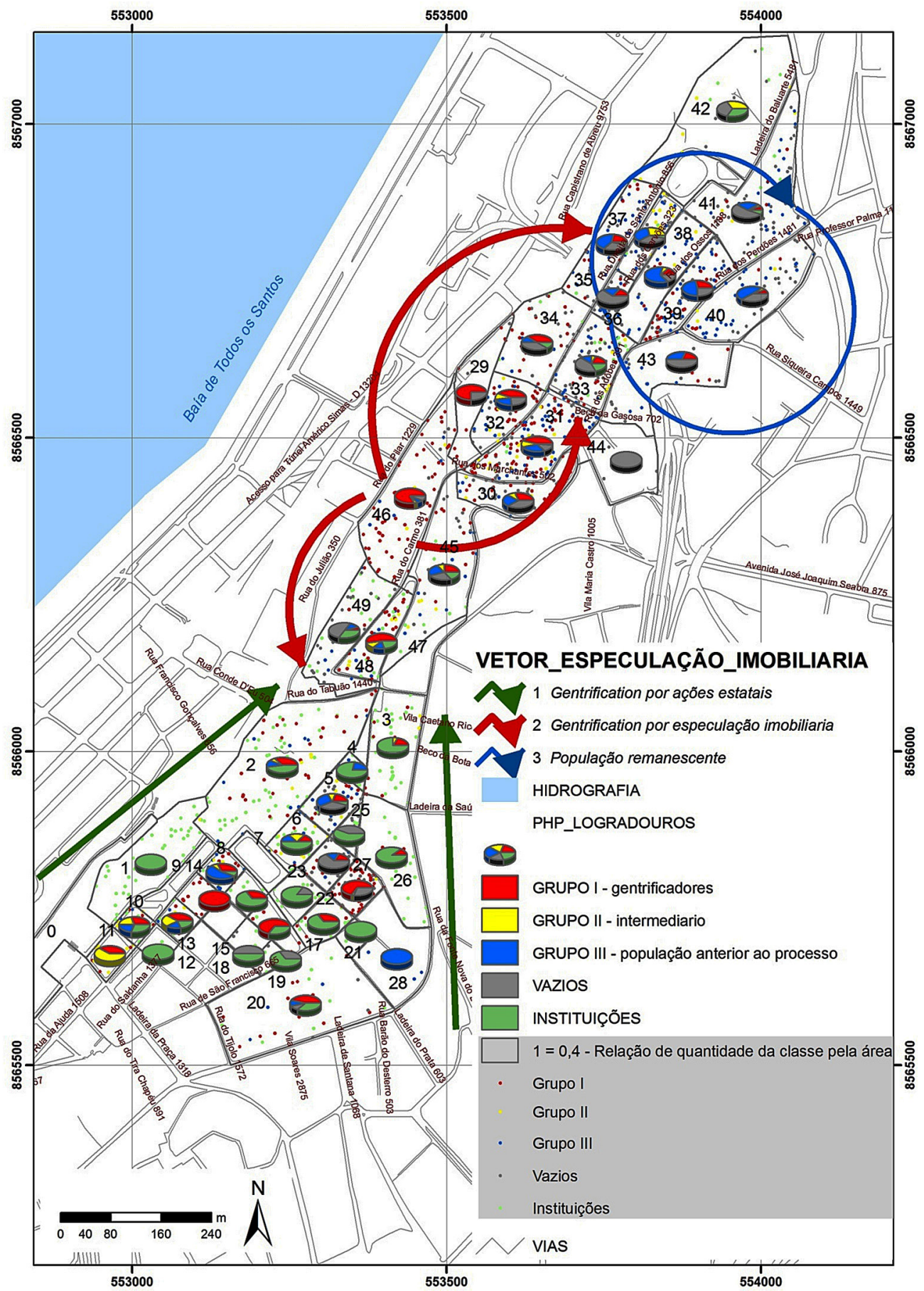

Fonte: Ribeiro (2011). 
Como consta no Quadro 1, em 1987 é criado através de um decreto estadual o Parque Histórico do Pelourinho (Bahia, 1987), a poligonal do Parque envolve área que abrange outros bairros além do próprio Pelourinho. É justamente aí que se dará o processo de gentrification, demonstrado no mapa do vetor da especulação imobiliária.

Ao observar o mapa do vetor da especulação imobiliária do Parque Histórico do Pelourinho é possível identificar uma semelhança com o caso relatado por Authier (2006), que tratou sobre o bairro de Saint-Georges, em Lyon. Da mesma forma que em Lyon ocorreu uma estratificação populacional, ficando a população remanescente concentrada ao norte, no caso do centro de Salvador, a população mais antiga ficou concentrada ao norte do bairro do Santo Antônio Além do Carmo - norte da poligonal. Contudo o processo se inicia no sul, a partir das ações de intervenção do Estado que ocorreram na década de 1990, com a conclusão de seis etapas e o início de uma sétima que se arrastou até o final do ano de 2008, quando, já em outro governo, foram retomados os trabalhos de restauração, seguindo novos moldes de ação, como o de colocar funcionários públicos habitando as casas que estavam em ruínas e foram restauradas (Quadro 2).

Quadro 2 - Impactos das ações no Parque Histórico do Pelourinho por etapa, até 2007

\begin{tabular}{|c|c|c|c|c|c|c|}
\hline Etapa & Área - $\mathbf{m}^{2}$ & Conclusão & $\begin{array}{c}\text { Móveis } \\
\text { restaurados }\end{array}$ & Quarteirões & $\begin{array}{l}\text { Moradores } \\
\text { indenizados }\end{array}$ & $\begin{array}{c}\text { Comerciantes } \\
\text { indenizados }\end{array}$ \\
\hline 1 & 33.053 & 1993 & 89 & 4 & 338 & 100 \\
\hline 2 & 11.088 & 1994 & 47 & 2 & 158 & 18 \\
\hline 3 & 12.476 & 1994 & 58 & 3 & 374 & 55 \\
\hline 4 & 47.525 & 1994 & 140 & 7 & 718 & 222 \\
\hline 5 & & 1996 & 130 & 2 & 45 & 22 \\
\hline 6 & & 1996 & 101 & 5 & 592 & 93 \\
\hline 7 & & Até 2007 & 141 & 10 & 357 & 98 \\
\hline
\end{tabular}

Fonte: Bonfim (2007), IPAC (2007). 
0 programa de recuperação do Pelourinho teve por meta a criação de uma espécie de shopping center a céu aberto. Inicialmente o espaço passou a ser frequentado pela população da cidade, ao mesmo tempo em que aumentou o fluxo de estrangeiros, principalmente vindos da Europa. Três motivos principais podem explicar isso. Primeiro, a valorização do euro em relação ao real. Segundo, devido ao investimento do Estado no turismo, tendo sido o próprio programa de recuperação um projeto com fins turísticos. E agregando valor a isso, a maior divulgação da cidade de Salvador pelo mundo, através do grupo Olodum que após gravar clipes com atrações internacionais como Paul Simon, teve seu apogeu com a participação no clipe They Don't Care About Us do popstar Michael Jackson, sendo o próprio Pelourinho um dos cenários do vídeo.

Com a vinda de estrangeiros, o vetor da especulação começou a correr em direção ao Norte, tendo sido o bairro do Carmo (Centro da Poligonal) o primeiro a ser procurado, principalmente pelos turistas que se interessavam em morar no lugar e certamente devido à proximidade do mesmo com o Pelourinho. Outro fator geográfico definitivo na escolha das edificações a serem adquiridas é o da visão que se pode ter para a Baía de Todos os Santos situada a oeste do Parque. A valorização do Carmo se intensificou ainda mais com a chegada do Hotel do Carmo, sendo o primeiro hotel histórico de luxo do país e pertencente ao grupo Pestana. Seria o início da ação do grande capital e do fim de uma gentrification até então esporádica, similar à definição de Smith. 0 vetor da especulação continuou seguindo em direção ao Norte, chegando ao bairro do Santo Antônio Além do Carmo, que merece um destaque especial para quantidade de empreendimentos comerciais voltados ao turismo, já identificados na área em 2007 (Figura 2).

De acordo com a pesquisa (Ribeiro, 2011), bairros que tinham características residenciais foram gradativamente se modificando a ponto de essa função ser reduzida a $36 \%$ da área (Figura 3). Em segundo lugar vem as edificações tidas em diversas situações que as caracterizam como vazias, representando $27 \%$ do total. Em terceiro, a função comercial com $22 \%$. Contudo, se as edificações com mais de uma unidade imobiliária tivessem as unidades vazias computadas no cálculo, o percentual desse grupo subiria consideravelmente. 
Figura 2 - Estabelecimentos do Santo Antônio Além do Carmo, em 2007

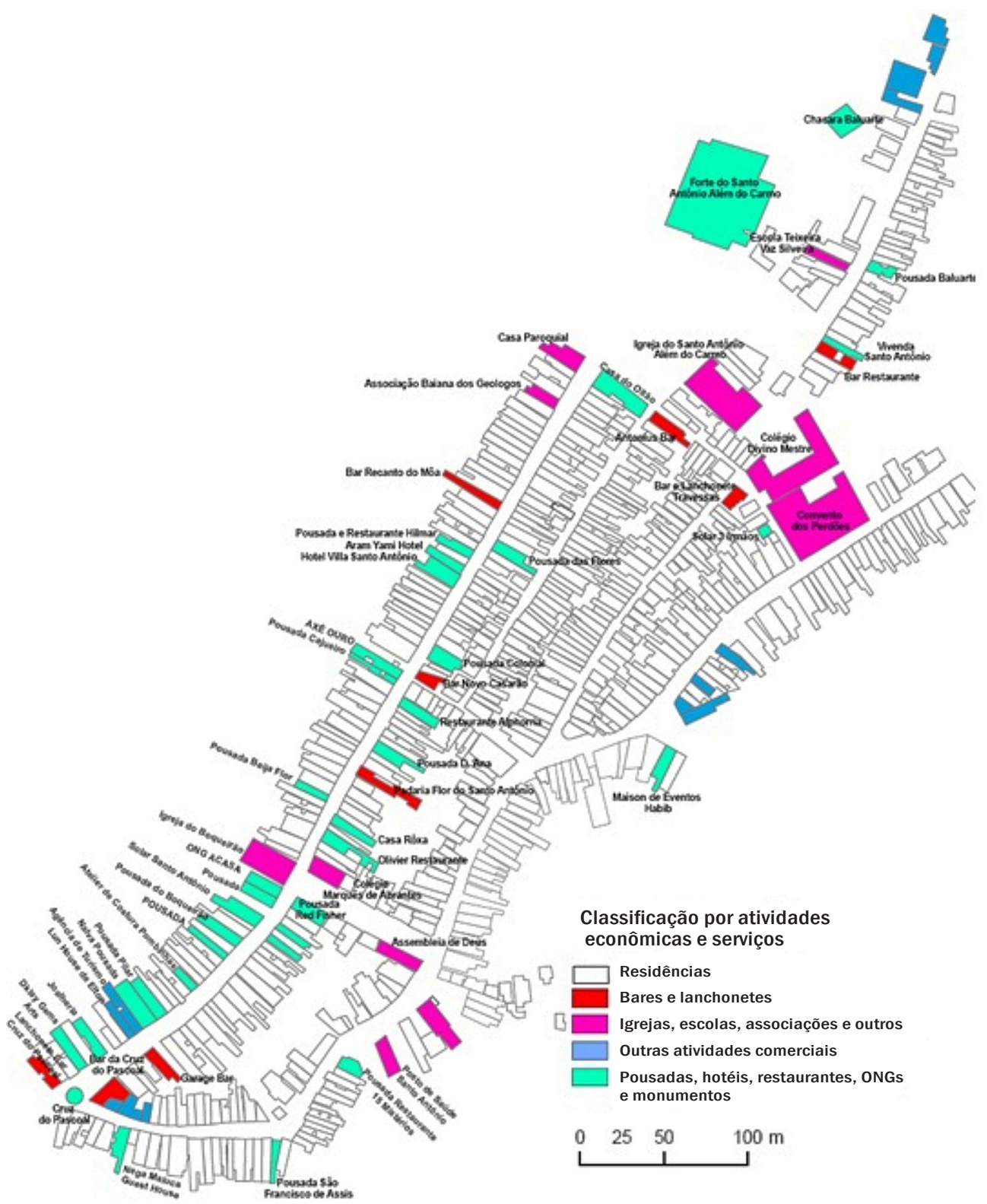

Fonte: Ribeiro (2008); Base: Conder, Sicar (1992). 
Figura 3 - Função e disfunção no Parque Histórico do Pelourinho

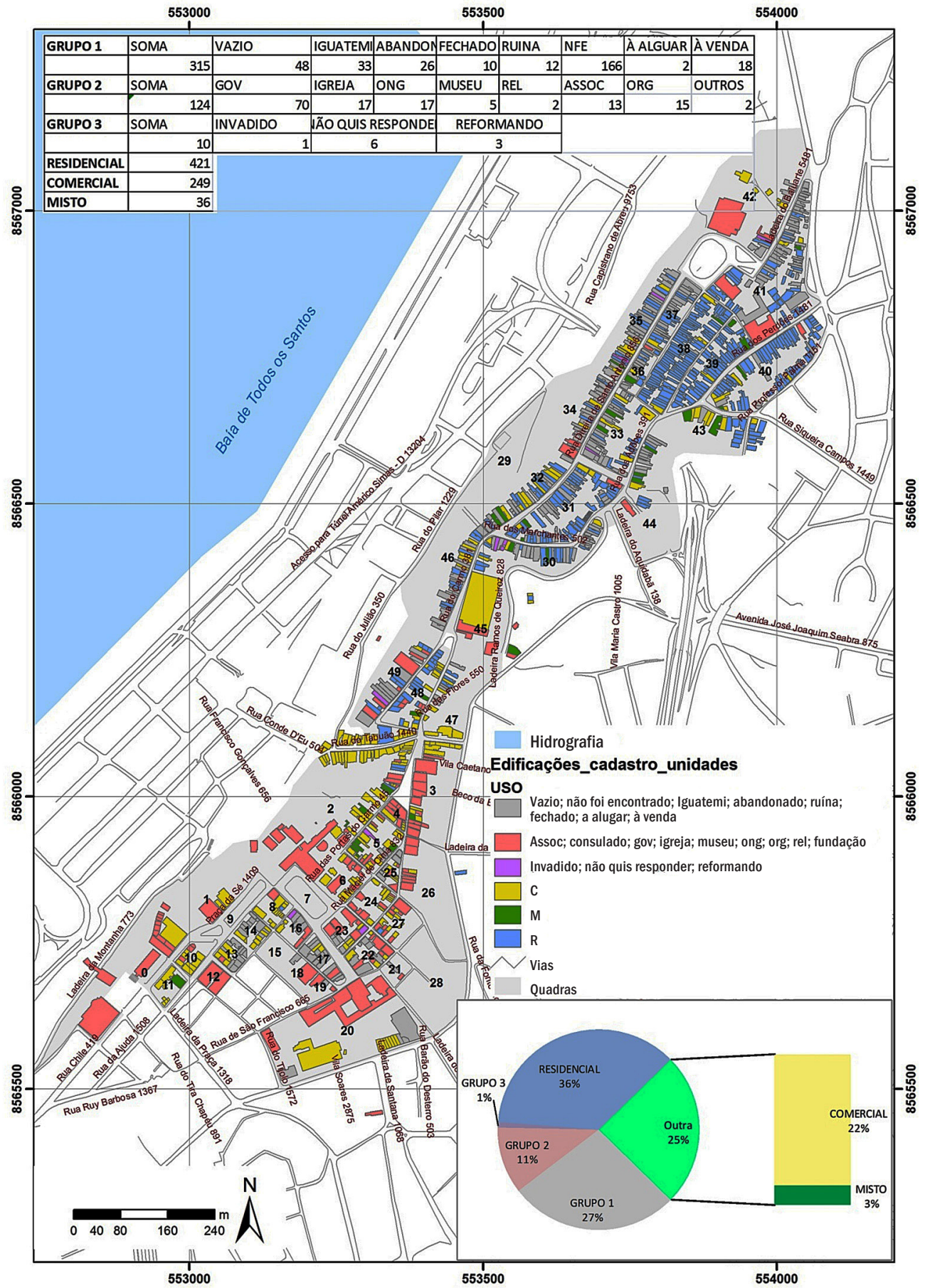

Fonte: Ribeiro (2011). Base: Conder, Sicar (1992). 
Enquanto no Pelourinho ocorreu a expulsão da população, seguida da instalação de equipamentos e instituições estatais, ongs e outras entidades, com destaque para pontos comerciais, no Carmo, aos poucos houve o esvaziamento das edificações devido ao alto preço dos imóveis. Já o Santo Antônio passou por diferentes fases. A primeira viu uma mescla entre a população mais antiga e os novos moradores que iam chegando e adquirindo os imóveis. Em um segundo momento, a especulação ficou forte e se viu crescer a quantidade de pousadas bem como o preço das propriedades que chegou a aumentar 20 vezes em alguns casos. Em um terceiro momento, já era perceptível uma redução significativa da população mais antiga. Associado a isso, o Estado começou a agir na área implementando alguns projetos que visavam valorizar o bairro. Nesse período, a ação do Estado pode ser comparada com o caso de Barcelona, pois a valorização e consequentemente expulsão dos moradores mais pobres foram induzidas. Um exemplo foi a reforma de alguns equipamentos urbanos no bairro do Santo Antônio que contribuiu para a valorização do lugar. Não se quer afirmar com isso que a indução da saída de moradores pela valorização do local foi intencionalmente provocada pelo Estado, mas chama-se a atenção para o fato de que foi uma consequência.

Ainda no mapa da função e disfunção (Figura 3) pode-se perceber que a quantidade de edificações vazias é bastante significativa em todo o Parque, do mesmo modo em que o Sul concentra um maior esvaziamento, que é agravado se considerarmos a quantidade de instituições que não funcionam à noite. No centro da poligonal, há a maior quantidade de moradores mais recentes do lugar. Esses moradores estariam enquadrados no grupo característico do processo de gentrification. Já ao norte da mesma, há uma maior concentração dos moradores mais antigos.

É válido chamar atenção para o fato de que um morador ser novo no lugar não o torna necessariamente um agente característico da gentrification. Do mesmo modo, moradores mais antigos podem se enquadrar no recorte social do processo. Isso reforça o conceito de upgrade trabalhado por Criekingen (2006), ao mesmo tempo em que demonstra a pluralidade, complexidade e relação da Teoria do Caos, com o processo de gentrification, como foi bem explicado por Bauregard (1996).

Na pesquisa realizada em 2011 (Ribeiro, 2011), a remoção populacional da área já era evidente, ao se observar que apenas $36 \%$ das edificações tinham função residencial e $3 \%$ função mista. Todavia, dos moradores da poligonal, uma parcela considerável se mudou para o local há menos de 18 anos, período que configuraria o recorte temporal associado à gentrification no Parque Histórico do Pelourinho. Ainda foi estabelecida uma margem temporal de segurança, de moradores que não seriam considerados nem como específicos do processo, nem como não sendo. Por fim, os moradores que estivessem residindo no local há mais de 25 anos foram considerados como estando fora do grupo relativo à gentrification. Com isso, percebe-se que metade dos moradores que sobraram no lugar já foram pessoas que substituíram antigos residentes. No mapa de tempo no lugar, estão computados também dados relativos a edificações com função comercial (Figura 4). 
Figura 4 - Tempo no lugar

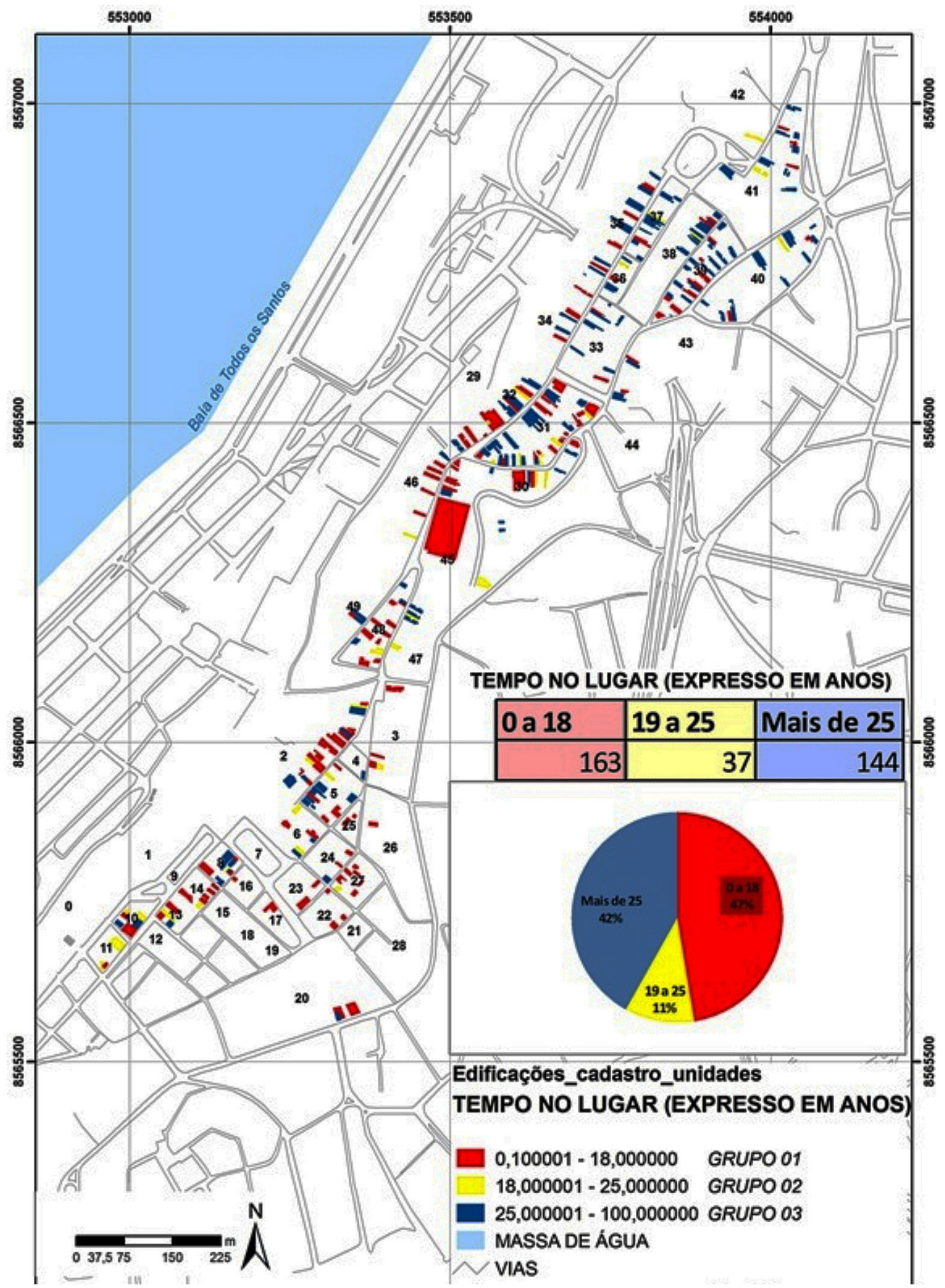

Fonte: Ribeiro (2011). Base: Conder, Sicar (1992). 
Combinando as informações do mapa de tempo no lugar com uma análise mais apurada dos dados (Tabela 1), é possível compreender melhor o perfil populacional dos três grupos temporais estabelecidos. Ao analisar o Quadro 2 , constata-se que o grupo dentro do tempo relativo ao processo de gentrification (grupo I) tem o maior número de estrangeiros, bem como uma razoável quantidade de pessoas oriundas de outros estados e municípios.

Já o grupo de moradores mais antigos (grupo III) conserva uma maior quantidade de nativos e uma distribuição equilibrada entre pessoas nascidas em outros bairros de Salvador ou outros municípios baianos. Ainda percebe-se uma quantidade menor de pessoas vindas de outros bairros e países. Excluindo o grupo II da análise e fazendo uma comparação entre outros dados relativos a cada grupo, percebeu-se que o padrão socioeconômico do grupo I é maior que o do grupo III. Ao checar as origens de cada grupo, uma nova constatação foi alcançada. Enquanto os estrangeiros do grupo I vieram em sua maioria de países como França, Itália, Dinamarca, Alemanha e Inglaterra, os estrangeiros do grupo III são em sua maioria portugueses e espanhóis. Esses estrangeiros apresentam um padrão financeiro superior à população oriunda de outros estados e municípios brasileiros do grupo III. Ao checar a origem da população vinda de outros estados do grupo III, constatou-se que a mesma é formada basicamente de outros estados nordestinos. Já os oriundos de outros estados do grupo I vieram em sua maioria do Sul e Sudeste.

A gentrification no Parque Histórico do Pelourinho fica caracterizada, então, por diversos fatores, que envolvem questões socioeconômicas e que ficam claramente definidos de acordo inclusive com a origem da população. Um exemplo claro disso é quando fazemos uma comparação do grau de conservação das edificações, de acordo com a origem de cada proprietário. Ao comparar os dados, percebeu-se que os estrangeiros não tinham, até aquele momento, edificação em estado ruim de conservação. Lembrando que a maioria dos estrangeiros compõe o grupo I (dentro do recorte de gentrification). A proporção se equilibra entre os oriundos de outros estados, municípios baianos e bairros soteropolitanos. No entanto, se separarmos a população vinda de outros estados de acordo com os grupos I e IIII, constataremos que não há edificações mal conservadas no grupo I. Essa lógica de padrão financeiro pode ser seguida para os outros casos (Gráfico 1).

Tabela 1 - Perfil da população, segundo a relação Tempo x Origem

\begin{tabular}{|c|c|c|c|c|c|c|c|}
\hline \multirow{2}{*}{ Quant. } & \multirow{2}{*}{ Origem } & \multicolumn{3}{|c|}{ Tempo no lugar } & \multicolumn{2}{|c|}{ Função } & \multirow{2}{*}{ Carro } \\
\hline & & Grupo I & Grupo II & Grupo III & Comerc/Mista & Residenc & \\
\hline 15 & Nativo & 4 & 1 & 10 & 10 & 5 & 5 \\
\hline 199 & Loc_SAL & 114 & 18 & 67 & 49 & 118 & 59 \\
\hline 96 & Mun_BA & 42 & 9 & 45 & 33 & 63 & 47 \\
\hline 30 & Est_BR & 12 & 4 & 14 & 14 & 16 & 10 \\
\hline 47 & Out_País & 34 & 6 & 7 & 30 & 17 & 18 \\
\hline
\end{tabular}

Fonte: Ribeiro (2011). 
Gráfico 1 - Conservação das edificações

segundo o perfil de origem da população

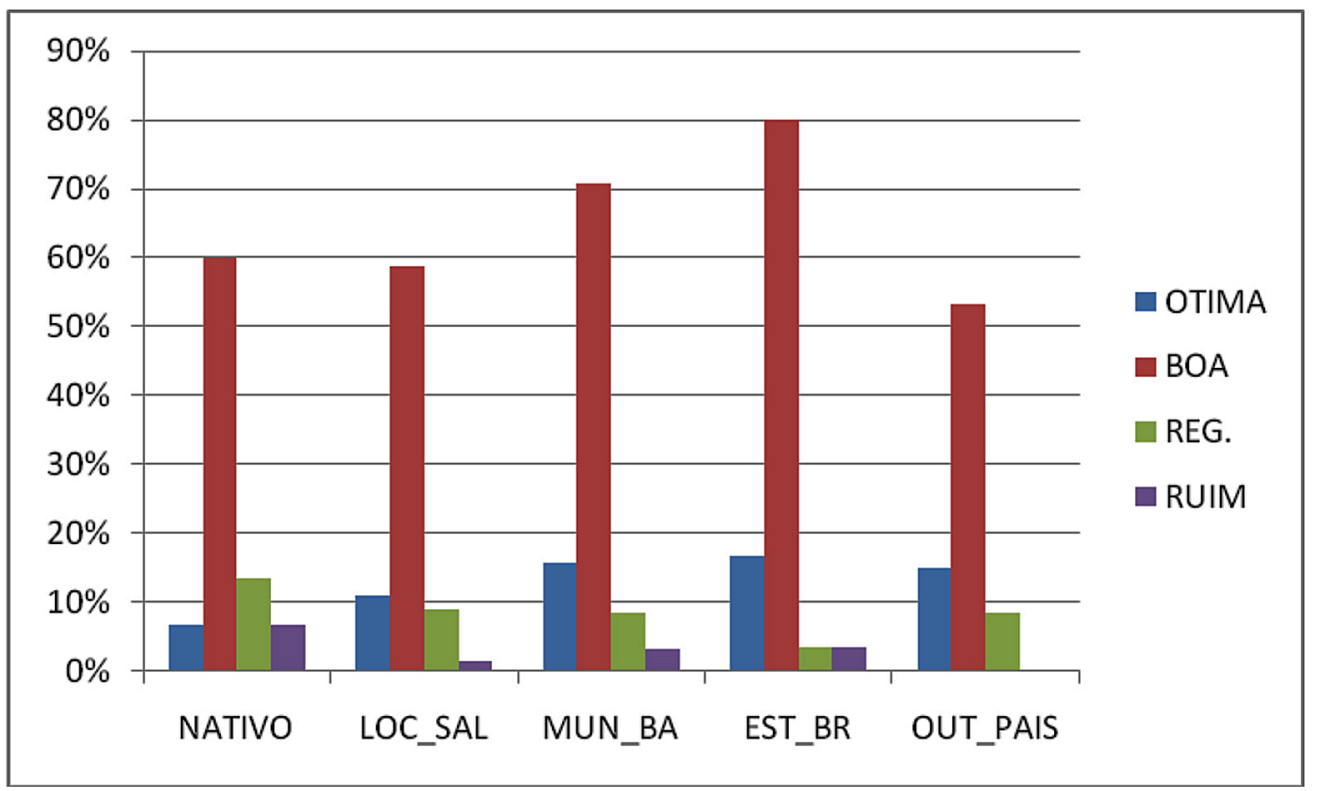

Fonte: Ribeiro (2011).

\section{0 fim da gentrification ou uma estratégia dos agentes imobiliários?}

Em 2008, o grupo Iguatemi da Bahia (Holding $L G R)$ iniciou a compra de edificações nos principais logradouros do Carmo e Santo Antônio Além do Carmo, a Rua do Carmo e a Rua Direita do Santo Antônio, respectivamente. A meta era adquirir 64 edificações com a ambição de fazer um projeto similar ao Pelourinho, só que trazendo grifes famosas e mesclando empreendimentos comerciais com residenciais. A principal figura à frente do grupo foi a da empresária Luciana Rique.
Depois de restaurar esse casarão aqui do Carmo, o que vai acontecer com ele? Ainda não sei. Eu estou com 35 imóveis aqui no Carmo. Meu projeto vai daqui, da Praça do Santo Antônio, até a Ladeira do Boqueirão. Quero fazer um mix de restaurantes, lojas bacanas, galerias de arte, espaços culturais, moradias (algumas de frente para o mar), escritórios... Eu ainda não defini o que será no casarão, mas ele é a âncora do projeto. (Muito, 2009, p. 11)

No decorrer da entrevista, a empresária menciona Londres e compara a ideia do projeto com o que ocorre na cidade inglesa. Tal menção traz mais um indício de que o projeto estava claramente enquadrado em moldes típicos de gentrification. Essa cópia do modelo londrino 
fica evidente quando a entrevistada faz a seguinte declaração:

Veja em Londres, por exemplo, todos os lugares bacanas tem gente morando, tem lojas bacanas. Acho que é isso que dá vida a um lugar. Não quero que seja como no Pelourinho, onde quem chega acaba tudo e pronto. Todos os investimentos vão embora. (Muito, 2009, p. 12)

Contudo as ações do Iguatemi encontraram problemas inesperados. Primeiramente, o grupo se deparou com a resistência por parte de alguns moradores em sair de suas casas. Mesmo com o assédio financeiro, muitos pessoas não querem vender suas residências. Ao mesmo tempo, não interessa ao Iguatemi comprar apenas uma parte das edificações. Além disso, a própria empresária se queixa de que não recebeu o apoio que esperava do governo para realização de seus planos. Com isso, percebe-se que o Estado também muda de posição no jogo da gentrification, confirmando mais uma vez a aleatoriedade e imprevisibilidade típica de um processo caótico. Os resultados da ação do Iguatemi foram desastrosos para a área. Não conseguindo comprar todas as casas, o grupo que já havia adquirido 35 edificações anunciou que as colocaria à venda e com isso contribuiu para ampliação do número de residências vazias no lugar. É importante lembrar que muitas propriedades adquiridas estavam alugadas por famílias que não gostariam de sair de suas casas, mas se viram intimadas a abandonar o lar.

Uma questão a ser levantada é se realmente houve desistência do grupo ou se isso não se trata de uma estratégia que visa desvalorizar o lugar. Um exemplo da possibilidade de que esteja havendo uma ação com intenção depreciativa da região foi a implementação do Ponto de Encontro. 0 Ponto de Encontro foi um centro de tratamento de viciados em drogas, localizado bem em meio a um bairro residencial - o Santo Antônio Além do Carmo - e que levantou muitas queixas dos moradores, pelo fato de os usuários ficarem no meio da rua, abordando a população e causando outros tipos de transtornos. É essencial salientar que o local onde foi implementado o projeto havia sido adquirido pelo Iguatemi e seria o ponto onde funcionaria o Instituto Newton Rique. No final de 2013 com a mobilização dos moradores, o Ponto de Encontro foi removido do bairro.

Não se dispõe de prova concreta para confirmar a insinuação de que a implementação de projeto como o Ponto de Encontro no bairro do Santo Antônio Além do Carmo faz parte de uma ação dos agentes econômicos que atuam na região visando expulsar os moradores que ali permanecem. No entanto, algumas questões podem ser levantadas reforçando argumentos para a suspeita. Primeiro, se o Iguatemi anunciou a venda das edificações em 2008, porque até hoje essa ação não foi realizada? Seria isso uma estratégia para desacelerar a especulação imobiliária? Algo similar foi relatado por Smith, quando menciona o caso de autores que chegaram a sugerir uma desgentrification. Segundo, estando a Copa do Mundo prestes a ser realizada, seria realmente do interesse desse grupo pôr à venda suas aquisições nesse momento? Terceiro, por que o Ponto de Encontro foi implementado em um prédio que seria instalado o Instituo Newton Rique? Ainda nessa questão, vale ressaltar que o Ponto de Encontro estava localizado próximo a algumas das famílias que não venderam suas 
residências e bem no Centro da Rua Direita do Santo Antônio. A incerteza do que ocorrerá no Parque Histórico do Pelourinho deixa muitas questões abertas. A resposta para elas dependerá das ações dos distintos agentes modeladores do espaço, tal como o Estado, os promotores imobiliários, os agentes econômicos, a população, a igreja e o grupo dos excluídos. Cabe aos pesquisadores continuarem acompanhando os fatos, ficando aqui uma contribuição para posteriores análises.

\section{Considerações finais}

Gentrification é um processo urbano, específico de localidades centrais e com características históricas que se destacam em relação ao conjunto urbanístico de uma cidade específica. No que diz respeito a seu recorte temporal, ele é coincidente com a pós-modernidade. Ao mesmo tempo, existe um público específico que compõe esse processo, uma vez que ele implica a substituição de uma população de baixo poder aquisitivo por outra de maior renda. A presença do grande capital e das influências da globalização também compõe as suas especificidades, no entanto o processo de gentrification terá diferentes peculiaridades a depender do lugar onde se estabelece.

0 Parque Histórico do Pelourinho, localizado na cidade de Salvador - Bahia, é um importante conjunto urbanístico, tombado pelo IPHAN e delimitado a partir de um decreto estadual de 1987. A partir da década de 1990, se iniciou nessa área uma espécie de gentrification forçada pelo Estado, que removeu a população de baixa renda da parte Sul e implementando ali um projeto de cunho turístico, com características comerciais. A consequência disso foi a expansão da valorização dos imóveis desse espaço urbano. Com isso, o vetor da especulação imobiliária e do processo de gentrification seguiu em direção ao Norte do Parque.

Tendo passado por uma fase esporádica e espontânea, o fenômeno se consolidou e conheceu a ação do grande capital, após a implementação do Hotel do Carmo pertencente ao grupo Pestana. Contudo, foi com a chegada do grupo Iguatemi que os bairros do Carmo e Santo Antônio conheceram a face mais perversa da gentrification. Hoje tendo quase metade de suas edificações esvaziadas e menos de $1 / 3$ de sua população mais antiga vivendo no lugar, o Parque passa por uma fase de desvalorização que pode ser fruto de uma ação dos agentes econômicos que atuam na região.

\section{Daniel de Albuquerque Ribeiro}

Universidade Federal da Bahia, Departamento de Geografia. Salvador/BA, Brasil.

daniel.ocazul@gmail.com 


\section{Referências}

AUTHIER, J. Y. (2006). "A gentrificação do bairro Saint-Georges, em Lyon: a convivência de mobilidades diferenciadas”. In: BIDOU-ZACHARIASEN, C. et al. De volta à cidade: dos processos de gentrificação às políticas de revitalização dos centros urbanos. São Paulo, Annablume.

BAHIA (1987). Decreto estadual no 7.984, de 4 de setembro.

BAUREGARD, R. A. (1996). "The chaos and complexity of gentrification". In: SMITH, N. e WILLIAMS, P. The new urban frontiers. Gentrification and the revanchist city. Nova York, Routledge.

BIDOU-ZACHARIASEN, C. et al. (2006). De volta à cidade: dos processos de gentrificação às políticas de revitalização dos centros urbanos. São Paulo, Annablume.

BONFIM, J. D. (2007). Salvador da Bahia: estudo geográfico do Centro Histórico e a sua integração sócio-urbana. Tese de doutorado. Salamanca, Universidade de Salamanca.

BORJA, J. e CASTELLS, M. (1997). Local \& global: management of cities in the information age. Londres, UNCHS (Habitat/ONU) e Earthscan Publications.

CLAVER, N. (2006). "A ciutat vella de Barcelona: renovação ou gentrificação?". In: BIDOU-ZACHARIASEN, C. et al. De volta à cidade: dos processos de gentrificação às políticas de revitalização dos centros urbanos. São Paulo, Annablume.

CRIEKINGEN, M. (2006). "A cidade renasce! Formas, políticas e impactos de revitalização residencial em Bruxelas". In: BIDOU-ZACHARIASEN, C. et al. De volta à cidade: dos processos de gentrificação às políticas de revitalização dos centros urbanos. São Paulo, Annablume.

HUNTER, J. C. (1998). O monge e o executivo. Rio de Janeiro, Sextante.

MELÉ, P. (2006). “(Re)investir nos espaços centrais das cidades mexicanas”. In: BIDOU-ZACHARIASEN, C. et al. De volta à cidade: dos processos de gentrificação às políticas de revitalização dos centros urbanos. São Paulo, Annablume.

RECLUS, E. (2010). Renovação de uma cidade, repartição dos homens. São Paulo, Imaginário.

REVISTA SEMANAL DO GRUPO A TARDE (2009). "Muito, abre aspas Luciana Rique empresária". Salvador, 18 out.

RIBEIRO, D. de A. (2008). Análise do processo de gentrificação na localidade do Santo Antônio Além do Carmo, de 1985 a 2007. Monografia em Geografia. Salvador, Universidade Católica do Salvador.

(2011). Gentrificação no Parque Histórico do Pelourinho, Salvador - Bahia. Dissertação de mestrado. Salvador, Universidade Federal da Bahia.

SCHOPENHAUER, A. (2009). A arte de escrever. Porto Alegre, L\&PM.

SMITH, N. (1996). "Alternatives to orthodoxy: invitation to a debate". In: SMITH, N. e WILLIAMS, P. The new urban frontiers. Gentrification and the revanchist city. Nova York, Routledge. 
SMITH, N. (2006). "A gentrificação generalizada: de uma anomalia local à "regeneração" urbana como estratégia urbana global”. In: BIDOU-ZACHARIASEN, C. et al. De volta à cidade: dos processos de gentrificação às políticas de revitalização dos centros urbanos. São Paulo, Annablume.

VASCONCELOS, P. de A. (2011). "Processos e formas sócio-espaciais das cidades: propostas para avançar no debate”. In: SILVA, S. B. de M. (org.). Estudos sobre dinâmica territorial, ambiente e planejamento. João Pessoa, Grafset.

Texto recebido em 16/out/2013

Texto aprovado em 17/abr/2014 